\title{
A Giant Mucinous Ovarian Cystadenoma- An Unusual Case Presentation
}

\author{
Rohan Sharukh Master ${ }^{1}$, Arpita Jaiswal ${ }^{2}$ \\ ${ }^{1}$ Department of Obstetrics and Gynaecology, DMIMS, Sawangi, Wardha, Maharashtra, India. \\ ${ }^{2}$ Department of Obstetrics and Gynaecology, DMIMS, Sawangi, Wardha, Maharashtra, India.
}

\section{PRESENTATION OF CASE}

A 30 yr. female was referred to AVBRH with difficulty in breathing. An abdominal computed tomography was done revealing a giant well defined peripherally cystic mass with solid lesions with enhancing septa within arising from the pelvis extending up to the epigastrium suggestive of complex ovarian cyst. Her only presenting complaint was abdominal distension which was increasing gradually over the past 78 months with tense abdomen and fullness in flanks with a difficulty in breathing. Patient was an operated case of right ovarian cystectomy 8-9 months back in which a $2.5 \mathrm{Kg}$ mass was extracted. Tumor marker Ca-125 levels were done which were at normal levels of $10.90 \mathrm{IU} / \mathrm{ml}$.

Exploratory laparotomy was done for the patient which revealed a partly solid partly cystic mass with solid lesions, measuring more than $40 \times 35 \mathrm{~cm}$. The mass was seen arising from the right ovary. Moderate ascites was found. A small nick was given over the cyst and about 5 liters of fluid suctioned out followed by delivering the cyst out of peritoneal cavity. There were no significant early or late postoperative complications. Patient withstood the procedure well and was shifted to the ward

A giant partly solid partly cystic mass measuring $40 \times 35 \mathrm{~cm}$ weighing 18100 gms was observed on pathology. Externally the tumor presented as a smooth surface. On dissection, the tumor presented a multicystic surface, with cystic spaces of various measure, separated by thin septa and filled with thick mucus. Uterus along with the left ovary, B/L fallopian tube and cervix did not reveal any pathological changes. No signs of infiltrative growth of the tumor, intraepithelial carcinoma (according with WHO classification revised by Scully) or stroma microinvasion was observed. The endometrium showed regular proliferative glands. Histologically the cervix fallopian tubes and omentum were unremarkable.

With today's imaging modalities ovarian tumours reaching massive sizes are not commonly encountered. Early detection leads to the diagnosis of tumours of small or medium size[1] the most common complication that being of a visible abdominal mass.[1,2] Furthermore complications including increased venous return, hypotension, cardiac failure, respiratory problems and intestinal distension may be encountered. Majority of the complications arise after the surgical procedure due to rapid changes in the body circulation and pulmonary oedema.[2] We report a case of a 30-yrs. old female who presented with difficulty in breathing, in front of a mucinous ovarian tumour of over 18100 gms. The surgical treatment and histopathological pattern are important for determining the outcome of this rare neoplasm. ${ }^{[3]}$
Corresponding Author: Dr. Rohan Sharukh Master, Department of Obstetrics and Gynaecology, DMIMS, Sawangi, Wardha,

Maharashtra, India.

E-mail: drrohanmaster1391@gmail.com

DOI: $10.14260 /$ jemds/2020/303

Financial or Other Competing Interests: None.

How to Cite This Article:

Master RS, Jaiswal A. A giant mucinous ovarian cystadenoma- an unusual case presentation. J. Evolution Med. Dent. Sci. 2020;9(16):1394-1396, 10.14260/jemds/2020/303 DOI:

Submission 13-12-2019,

Peer Review 01-04-2020,

Acceptance 08-04-2020,

Published 20-04-2020.

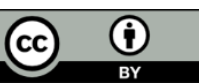




\section{DISCUSSION}

Mucinous cystadenomas in most cases are unilateral and when they are diagnosed in Stage I, present a recurrence rate of $1 \%{ }^{[4]}$ This case of a giant mucinous tumor confirms the rarity and peculiarity of this presentation. ${ }^{[5]} \mathrm{A}$ giant mass of this size compresses adjacent organs. The patient may also present with gastric compression, early satiety and dysuria.in this case the patient's only presenting complaint was that of breathlessness. [6,7,8] The following symptoms help reaching a diagnosis of a giant ovarian mass. It is to be noted that the weight of lesion is not related with malignancy risk, as demonstrated by histopathological analysis. Operating in these cases involves an element of risk those being risk of cardiac failure, respiratory failure sepsis and pulmonary embolism. ${ }^{[9,10,4]}$ In certain cases fluid aspiration is done in order to reduce sudden intrabdominal pressure changes in postoperative period. Drainage of the mass is an option in cases of high wall tension.[11] Different histological patterns and an array of clinical manifestations are common in giant ovarian tumors most being mucinous heterogeneous grade, with different patterns of borderline type that may also be important to reach a prognosis.[10,12]
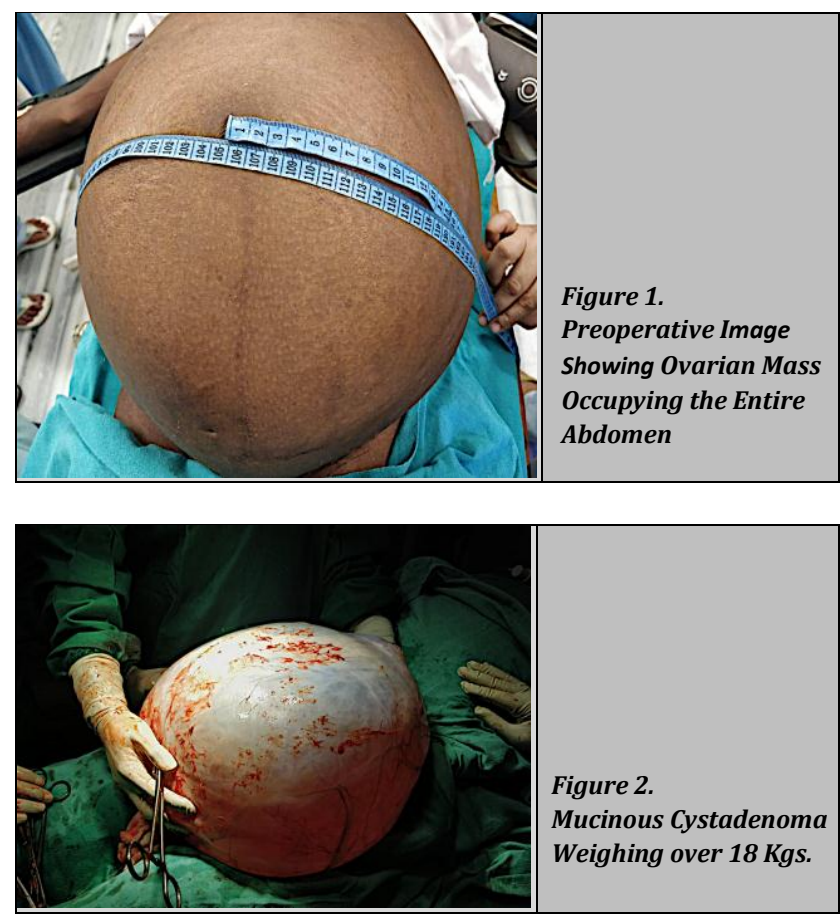

Figure 2.

Mucinous Cystadenoma Weighing over $18 \mathrm{Kgs}$.

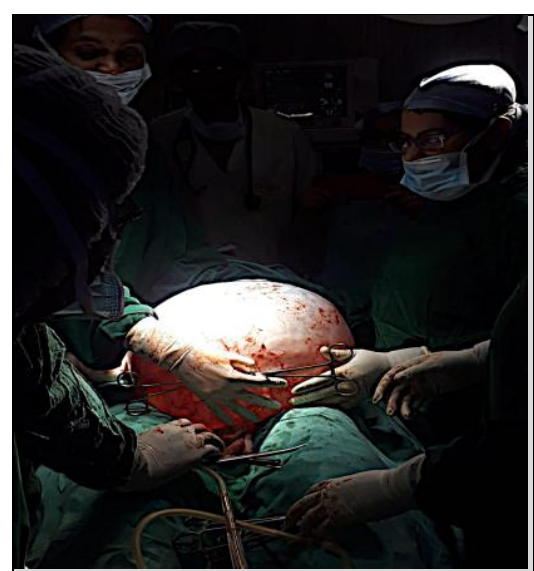

Figure 3.

The Large Mass is Removed

Intact Preventing Any Spillage into the Abdominal Cavity

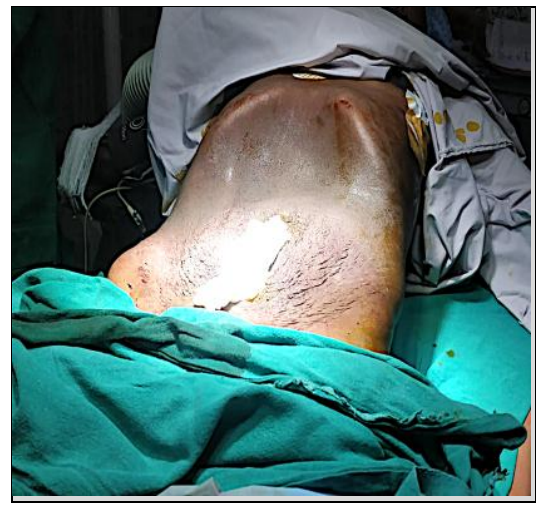

Figure 4.

Postoperative View of the Patient's Abdomen Revealing the Extent to Which the Mass Was Occupying the Abdominal Cavity.

In contrast to the invasive variety, mucinous cystadenomas are mostly unilateral.[13] Tumors of the bilateral variety are associated with an increased propensity for metastasis.[12] The overall outcome of mucinous tumors is favourable including those in which there is stromal invasion according with FIGO classification.[14] Recent studies on the histopathology of these tumors favouring transformation from benign to invasive carcinomas are represented by the stage of mucinous carcinogenesis.[15]

\section{CONCLUSIONS}

Mucinous cystadenomas are ovarian tumors requiring comprehensive management in order to prevent highrisk operative complications. This case report is indicative for the presence of difficulty in breathing as the chief complaint although the lesion size, the histopathological features being mucinous associated with a favourable prognosis, the comprehensive and clinical post operative management of the present case resulting in good clinical outcome for the same.

\section{REFERENCES}

[1] Kincey J, Westin SN, Zhao B, et al. Surgical removal of a gigantic abdominal mass: a multidisciplinary approach. Obstet Gynecol 2011;117(2 Pt 2):508-12.

[2] Farinetti A, Buttazzi A, Tazzioli G, et al. Giant ovarian cyst. A case weighing $23 \mathrm{~kg}(50.6 \mathrm{lb})$. Literature review. Minerva Chir 2003;58(2):261-5.

[3] Rodríguez IM, Prat J. Mucinous tumors of the ovary: a clinicopathologic analysis of 75 borderline tumors (of intestinal type) and carcinomas. Am J Surg Pathol 2002;26(2):139-52.

[4] Riopel MA, Ronnett BM, Kurman RJ. Evaluation of diagnostic criteria and behavior of ovarian intestinaltype mucinous tumors: atypical proliferative (borderline) tumors and intraepithelial, microinvasive, invasive and metastatic carcinomas. Am J Surg Pathol 1999;23(6):617-35.

[5] Cîrstoiu MM, Sajin M, Secară DC, et al. Giant ovarian mucinous cystadenoma with borderline areas: a case report. Rom J Morphol Embryol 2014;55(4):1443-7.

[6] Agha RA, Fowler AJ, Saeta A, et al. The SCARE statement: the consensus-based surgical case report guidelines. Int J Surg 2016:34:180-6. 
[7] Güraslan H, Yaşar L, Ekin M, et al. A successful management of a giant mucinous ovarian tumor with intraoperative controlled fluid aspiration. Eur J Gynaecol Oncol 2015;36(5):615-7.

[8] Einenkel J, Alexander H, Schotte D, et al. Giant ovarian cysts: is a pre and intra operative drainage an advisable procedure? Int J Gynecol Cancer 2006;16(6):2039-43.

[9] Kondi-Pafiti A, Bakalianou C, Dastamanis C, et al. A giant ovarian mucinous cystic neoplasm weighing 8,500 grams with functional stroma. A case report and review of literature. Eur J Gynecol Oncol 2009;30(6):704-6.

[10] De Nictolis M, Montironi R, Tommasoni S, et al. Benign, borderline and well-differentiated malignant intestinal mucinous tumors of the ovary: a clinicopathologic, histochemical, immunohistochemical and nuclear quantitative study of 57 cases. Int J Gynecol Pathol 1994;13(1):10-21.
[11] Dotters DJ, Katz VL, Currie J. Massive ovarian cyst: a comprehensive surgical approach. Obstet Gynecol Surv 1988;43(4):191-6.

[12] Ronnett BM, Kurman RJ, Zahn CM, et al. Pseudomyxoma peritoneiin women: a clinicopathologic analysis of 30 cases with emphasis on site of origin, prognosis and relationship to ovarian mucinous tumors of low malignant potential. Hum Pathol 1995;26(5):509-24.

[13] Prat J, FIGO Committee on Gynecologic Oncology. Abridged republication of FIGO's staging classification for cancer of the ovary, fallopian tube, and peritoneum. Cancer 2015;121(19):3452-4.

[14] Mayr D, Hirschmann A, Löhrs U, et al. KRAS and BRAF mutations in ovarian tumors: a comprehensive study of invasive carcinomas, borderline tumors and extraovarian implants. Gynecol Oncol 2006;103(3):883-7.

[15] Tropé C, Davidson B, Paulsen T, et al. Diagnosis and treatment of borderline ovarian neoplasms "the state of the art". Eur J Gynaecol Oncol 2009;30(5):471-82. 